\title{
Daftari sabz. Ed. Abdulhai Mahmadaminov, Douchanbe, Nashriioti « Sino », 2004, 575 p., ill., glossaire, index. [Le cahier vert]
}

\section{Stéphane A. Dudoignon}

\section{(2) OpenEdition}

1 Journals

\section{Édition électronique}

URL : http://journals.openedition.org/abstractairanica/6539

DOI : 10.4000/abstractairanica.6539

ISSN : 1961-960X

Éditeur :

CNRS (UMR 7528 Mondes iraniens et indiens), Éditions de l'IFRI

\section{Édition imprimée}

Date de publication : 15 mai 2006

ISSN : 0240-8910

Référence électronique

Stéphane A. Dudoignon, «Daftari sabz. Ed. Abdulhai Mahmadaminov, Douchanbe, Nashriioti « Sino », 2004, 575 p., ill., glossaire, index. [Le cahier vert] », Abstracta Iranica [En ligne], Volume 27 | 2006, document 332, mis en ligne le 02 janvier 2007, consulté le 25 septembre 2020. URL : http:// journals.openedition.org/abstractairanica/6539; DOI : https://doi.org/10.4000/abstractairanica.6539

Ce document a été généré automatiquement le 25 septembre 2020.

Tous droits réservés 


\title{
Daftari sabz. Ed. Abdulhai Mahmadaminov, Douchanbe, Nashriioti « Sino », 2004, 575 p., ill., glossaire, index. [Le cahier vert]
}

\author{
Stéphane A. Dudoignon
}

1 Un philologue de l'Université d'Etat du Tadjikistan (Douchanbe) propose une édition « scientifique et critique » (matni ilmiu intiqodì) du « cahier vert », collection manuscrite anthume de l'œuvre en vers d'un religieux et mystique tadjik de Kulab, Sāmi' ĀdīnaZāda «Khatlānī » (1907[?]-95). Les textes sont précédés (pp. 6-163) d'une importante biographie, basée sur des témoignages oraux de disciples et de proches d'Ādīna-Zāda (parmi lesquels le musicien 'Umar Tīmūr), ainsi que sur un nombre important d'articles de presse consacrés à cette grande figure de l'islam soviétique au sud du Tadjikistan. La plupart de ces témoignages et écrits, cependant, ne concernent que la dernière période de la vie d'Ādīna-Zāda, pendant la perestroïka et les premières années d'indépendance du Tadjikistan : ses années de formation à Boukhara, son long exil en Afghanistan, sa déportation en Sibérie et, surtout, son rôle exact dans le cercle (mahfil) clandestin des «Cœurs clairs» (rawshan-dilān) à Kulab, autour de l'éminente personnalité du poète mystique Mīrzā Latīf Rahīm-Zāda (1902-67), restent insuffisamment documentés, alors même que les témoignages oraux que l'on peut recueillir aujourd'hui à Kulab concordent rarement sur tous ces points. A propos de la période la plus récente, on peut regretter également l'absence de curiosité de la plupart des observateurs sur le positionnement théologique et politique curieux d'Ādīna-Zāda, ancien pensionnaire du goulag, puis proche du théologien réformiste clandestin Mawlawī Hindūstānī (1892-1989), mais qui s'est rangé en 1991 du côté des milices procommunistes et de leurs seigneurs de la guerre réputés les plus impitoyables, contre les représentants du parti du Renouveau Islamique (voir pp. 368-9 une marthiyya du «Commandant» Langarī Langariev) : il y a là des choses qui relèvent probablement des segmentations communautaires bien particulières, souvent violentes, de la ville et de la région de 
Kulab à la fin de la période soviétique et à l'époque actuelle, sur lesquelles les mémorialistes tadjiks semblent peu pressés de se pencher.

2 Les textes édités en caractères cyrilliques sont répartis selon leur forme respective : ghazals (pp. 166-220, dont certains sont des hommages à des figures contemporaines, tel Mullā Ghulām « Qawwāl », membre du cercle des Cœurs clairs), musammats (parmi lesquels plusieurs sur la base de ghazals du poète d'Oura-Teppa Jawharī Istrawshānī [m. 1944], et plusieurs musaddas renvoyant à des événements de l'histoire contemporaine du Tadjikistan : manifestations violemment réprimées de février 1990 à Douchanbe, libéralisation du culte islamique, etc.), une quinzaine de marthiyyas (dont deux consacrées à Mīrzā Latīf Rahīm-Zāda, mais une aussi au poète lauréat de la période Brejnev, Mīrzā Tursūn-Zāda), enfin quelques pièces de forme mathnawī, qit $a$, qasìda, un petit nombre de poèmes bilingues persan et ouzbek (shìr ù shakar) et quelques poésies en ouzbek. L'ensemble, enrichi de très nombreuses notes philologiques, porte un témoignage extrêmement précieux d'un certain état de la culture religieuse et sur les sociabilités alternatives au Tadjikistan pendant la seconde moitié de la période soviétique. Dans l'attente d'une édition critique de l'œuvre complète d'Ādīna-Zāda, les textes recueillis ici fournissent aux historiens des éléments de réflexion extrêmement précieux sur les relations complexes entre culture officielle et contre-culture, et sur le poids des segmentations infra-communautaires en Asie Centrale soviétique.

INDEX

Thèmes : 11.3. Littérature Asie centrale

\section{AUTEURS}

STÉPHANE A. DUDOIGNON

CNRS - Paris 